\title{
Hip morphology influences the pattern of damage to the acetabular cartilage
}

\author{
FEMOROACETABULAR IMPINGEMENT AS A CAUSE OF EARLY \\ OSTEOARTHRITIS OF THE HIP
}

\begin{abstract}
M. Beck, M. Kalhor, M. Leunig, R. Ganz
\end{abstract}

From the University of Bern, Bern, Switzerland

\footnotetext{
M. Beck, MD, Orthopaedic Surgeon

M. Leunig, MD,

Orthopaedic Surgeon

R. Ganz, MD, Professor,

Orthopaedic Surgeon

Department of Orthopaedic

Surgery

University of Bern

Inselspital, 3010 Bern,

Switzerland.

M. Kalhor, MD, Visiting

Fellow, Orthopaedic

Surgeon

Iran University of Medical

Sciences, Firouzgar Medical

Center, Tehran 15943, Iran.

Correspondence should be sent to $\mathrm{Dr}$ M. Beck; e-mail: martin.beck@insel.ch
}

(C)2005 British Editorial Society of Bone and Joint Surgery doi:10.1302/0301-620X.87B7. $15203 \$ 2.00$

$J$ Bone Joint Surg $[\mathrm{Br}]$ 2005;87-B:1012-18.

Received 9 December 2003; Accepted after revision 7 October 2004

\begin{abstract}
Recently, femoroacetabular impingement has been recognised as a cause of early osteoarthritis. There are two mechanisms of impingement: 1) cam impingement caused by a non-spherical head and 2) pincer impingement caused by excessive acetabular cover. We hypothesised that both mechanisms result in different patterns of articular damage. Of 302 analysed hips only $\mathbf{2 6}$ had an isolated cam and $\mathbf{1 6}$ an isolated pincer impingement. Cam impingement caused damage to the anterosuperior acetabular cartilage with separation between the labrum and cartilage. During flexion, the cartilage was sheared off the bone by the non-spherical femoral head while the labrum remained untouched. In pincer impingement, the cartilage damage was located circumferentially and included only a narrow strip. During movement the labrum is crushed between the acetabular rim and the femoral neck causing degeneration and ossification.

Both cam and pincer impingement lead to osteoarthritis of the hip. Labral damage indicates ongoing impingement and rarely occurs alone.
\end{abstract}

Femoroacetabular impingement as a cause of early degenerative changes in the hips of young adults has been recognised and described only recently. ${ }^{1-6}$ It reflects abutment of the acetabular rim and the femoral neck and is associated with abnormalities of the proximal femur ${ }^{1,2,5}$ and of the acetabulum. , 7,8 The femoral abnormalities are characterised by decreased or absent waisting of the junction of the femoral neck and head. This appears as an aspherical junction between the head and neck, with an increased radius of the femoral epiphysis as it joins the neck. These changes have been named the pistol-grip ${ }^{9}$ or tilt deformity. ${ }^{10}$ They are also seen in slipped capital femoral epiphysis ${ }^{3}$ or in any hip in which the femoral neck is too large. ${ }^{2}$ They cause a cam-type impingement in which the abnormal junction is driven into the acetabulum producing damage to the cartilage in the area of the anterosuperior rim. ${ }^{2,3,6}$

Abnormalities of the acetabulum associated with impingement include excessive cover of the head as is seen in retroversion ${ }^{7,8}$ or in a deep acetabulum. ${ }^{2,6}$ In these hips the femoral neck that is normal impinges against an overcovering acetabulum, resulting in linear contact between the neck and the acetabular rim. This mechanism has been termed pincer impingement. ${ }^{2,6}$

We hypothesised that cam impingement results in a pattern of articular damage which differs from that seen in impingement resulting from acetabular overcover. We have investigated both mechanisms of femoroacetabular impingement.

\section{Patients and Methods}

In order to obtain unequivocal data, two welldefined hip configurations were selected, which represent most closely the two mechanisms of impingement. The pistol-grip deformity was selected as the cam impingement model (Fig. 1) and coxa profunda as typical of pincer impingement (Fig. 2). The latter is defined as a hip in which the floor of the fossa acetabuli touches the ilioischial line. ${ }^{11}$ To exclude overlap between the two mechanisms, only pistolgrip deformities with a normal acetabulum and coxa profunda with a normal proximal femur were selected.

Between June 1996 and April 2001, surgical dislocation of the hip for the treatment of intra-articular pathology was performed by the senior author (RG) or under his direct supervision in 302 hips. Of these, 37 with traumatic or post-traumatic conditions, 14 with avascular necrosis and seven which had undergone previous surgery were excluded leaving 244 hips in the study.

The pre-operative pelvic radiograph and the lateral cross-table radiograph of the hip were obtained for each patient. The pelvic radio- 


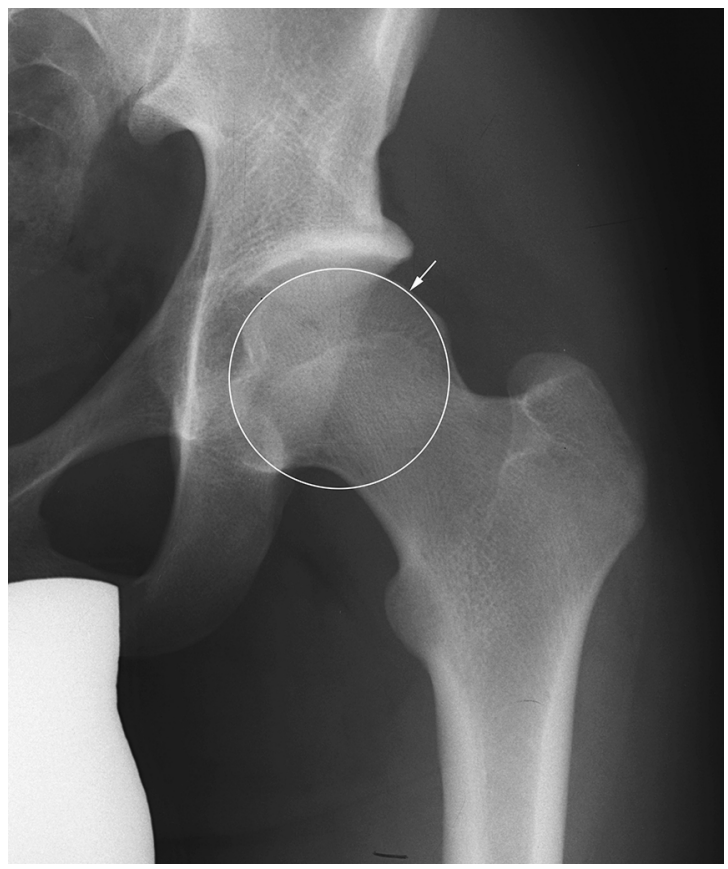

Fig. 1a

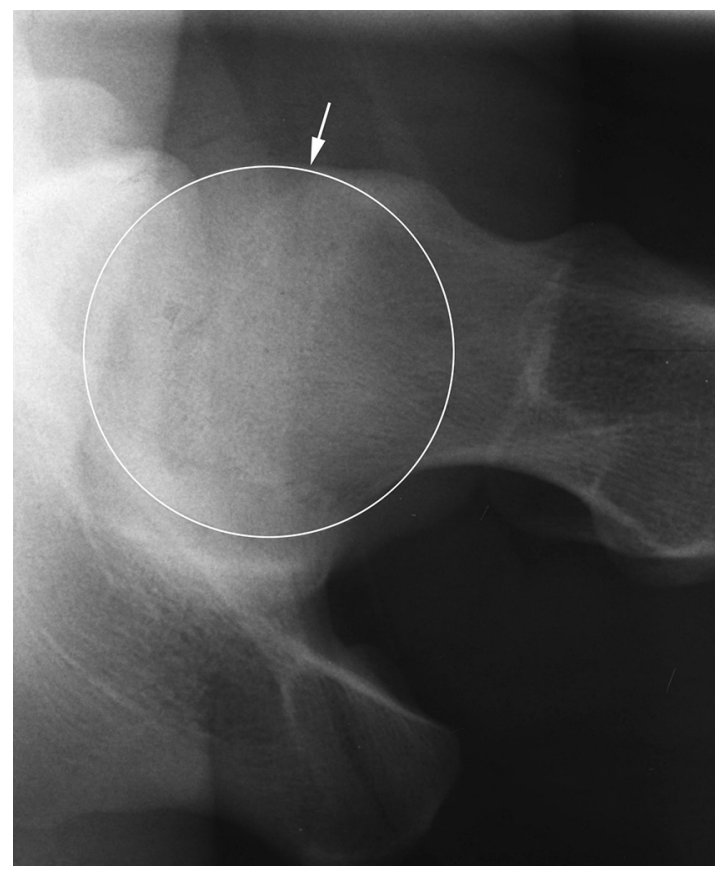

Fig. 1b

Radiographs of a hip with cam impingement presenting as a pistol-grip deformity. Figure 1a - The anteroposterior view showing asphericity of the femoral head as the area which extrudes from the circle laterally (arrow). Figure $1 \mathrm{~b}-\mathrm{The}$ lateral cross-table view showing asphericity of the femoral head extending from the circle (arrow).

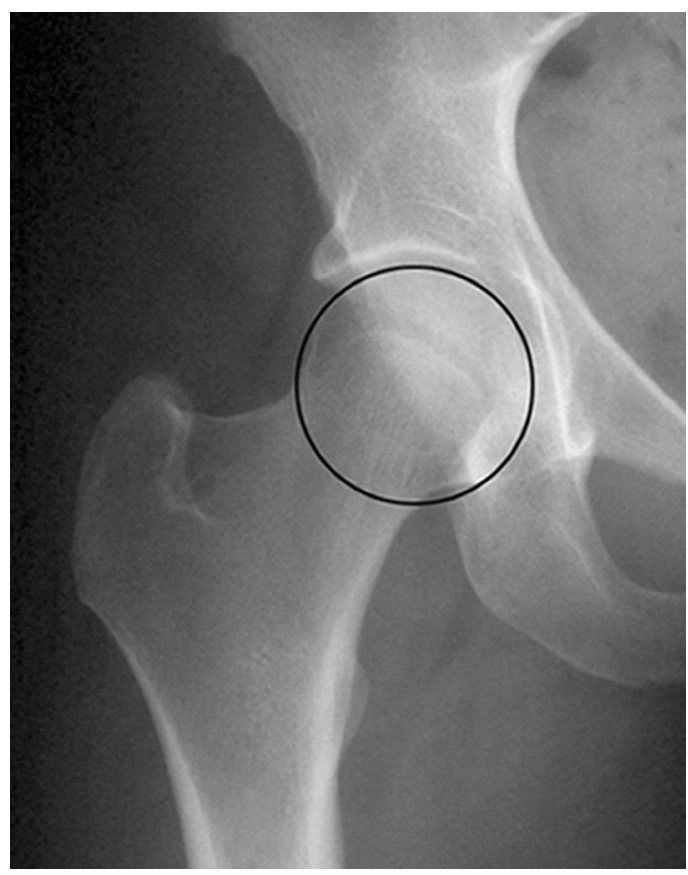

Fig. $2 a$

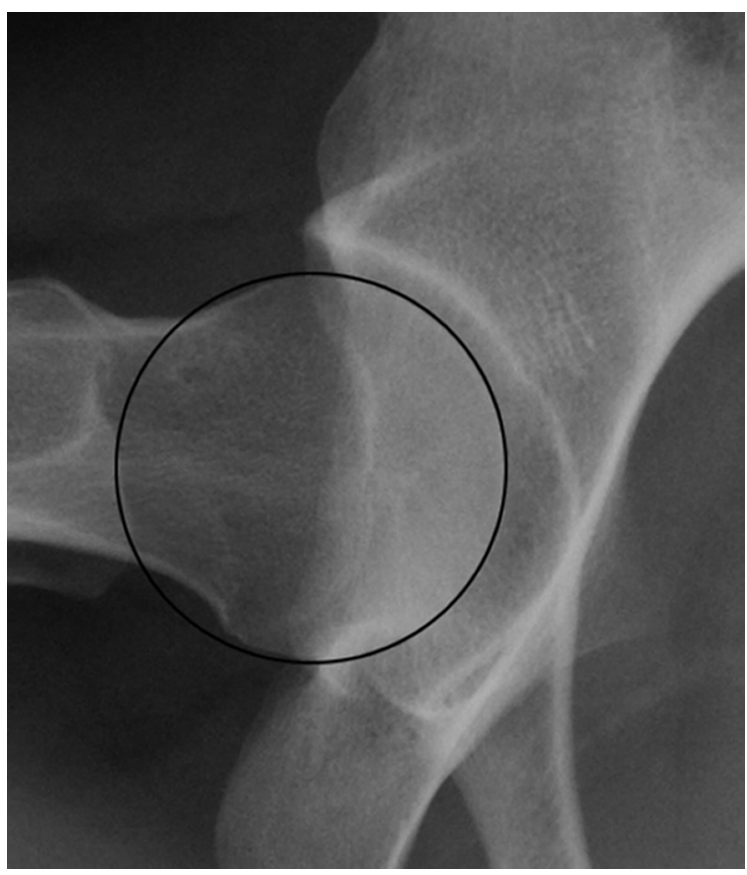

Fig. $2 b$

Radiographs of a hip with pincer impingement showing coxa profunda with ossification of the acetabular labrum a) anteroposterior and b) lateral views. The head is spherical in both planes. 
Table I. Classification of damage to cartilage modified from Beck et al ${ }^{6}$

\begin{tabular}{|c|c|}
\hline Description & Criteria \\
\hline Normal & Macroscopically sound cartilage \\
\hline Malacia & Roughening of surface, fibrillation \\
\hline Debonding & $\begin{array}{l}\text { Loss of fixation to the subchondral bone, macroscopically } \\
\text { sound cartilage; carpet phenomenon }\end{array}$ \\
\hline Cleavage & $\begin{array}{l}\text { Loss of fixation to the subchondral bone; frayed edges, } \\
\text { thinning of the cartilage, flap }\end{array}$ \\
\hline Defect & Full-thickness defect \\
\hline
\end{tabular}

Table II. Classification of labral damage

\begin{tabular}{ll}
\hline Description & Criteria \\
\hline Normal & $\begin{array}{l}\text { Macroscopically sound labrum } \\
\text { Thinning or localised hypertrophy, fraying, discolor- } \\
\text { ation }\end{array}$ \\
$\begin{array}{l}\text { Full-thickness tear } \\
\text { Complete avulsion from the acetabular rim } \\
\text { Detachment }\end{array}$ & $\begin{array}{l}\text { Separation between acetabular and labral cartilage, } \\
\text { preserved attachment to bone } \\
\text { Ossification }\end{array}$ \\
\hline
\end{tabular}

Table III. Hips excluded from the study

\begin{tabular}{lc}
\hline Exclusion criteria & Number \\
\hline Insufficient/incomplete radiographs & 36 \\
Perthes' disease & 7 \\
OA $\geq 1$ according to Tönnis ${ }^{13}$ & 52 \\
Total excluded & 95 \\
\hline
\end{tabular}

graph was accepted if it was orthograde, the distance between the symphysis pubis and coccyx measured 1 to 1.5 $\mathrm{cm}$ and the $\mathrm{x}$-ray beam was centred on the symphysis. ${ }^{12}$ Patients with incomplete or inadequate pre-operative radiographs were excluded.

Cartilage damage increases with progressive radiographic signs of degeneration and finally damage is so extensive that the information about the starting point of joint degeneration is obscured. Therefore, only hips with minor radiological changes, narrowing or osteophytes equivalent to an osteoarthrosis grade less than 1 according to the classification of Tönnis, ${ }^{13}$ were included. Those with femoroacetabular impingement as a result of Perthes' disease were excluded.

The shape of the femoral head was classified as normal if the femoral head was spherical in both planes and the neck offset measured less than $7 \mathrm{~mm}$ on the lateral crosstable view. ${ }^{14} \mathrm{~A}$ hip was classified as aspherical if, on the lateral cross-table view, the head protruded out of a circle drawn around the head and extended anteriorly in a convex shape to the base of the neck. In a hip with a pistol-grip deformity ${ }^{9}$ the femoral head additionally extends laterally

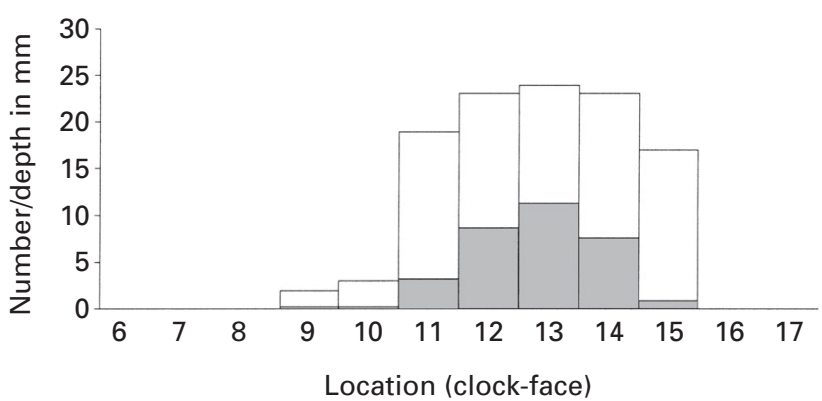

Fig. 3

Distribution (white) and depth (grey) of the cartilage lesions in the hips with a cam impingement $(n=26)$.

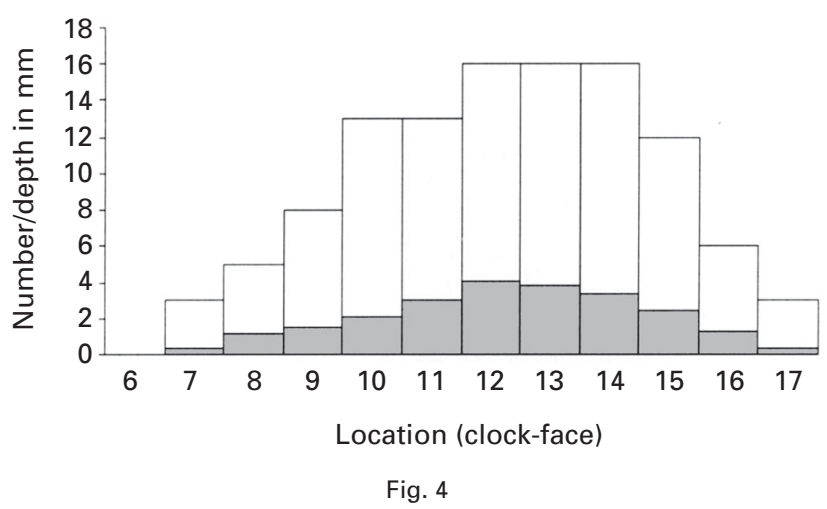

Distribution (white) and depth (grey) of the cartilage lesions in the hips with a pincer impingement $(n=16)$.

in a convex shape to the base of the neck. A varus or valgus deformity was present if the centre of rotation was more than $5 \mathrm{~mm}$ below or above the tip of the greater trochanter. The acetabulum was classified as retroverted if the anterior border crossed the posterior border medial to the lateral edge of the acetabulum, ${ }^{7}$ as protrusio if the femoral head overlapped the ilioischial line medially, and as profunda if the floor of the fossa acetabuli touched the ilioischial line. ${ }^{11}$

Damage to labral, acetabular and femoral head cartilage was evaluated after surgical dislocation. The labral and acetabular cartilage was evaluated for stability and other lesions (Tables I and II). The extent of a cartilage lesion along the acetabular rim was defined as the width, and the extension from the acetabular rim towards the acetabular fossa, as the depth. Pathological changes were documented on a diagram of the acetabulum which was divided into 12 sectors corresponding to a clockface, the six o'clock being located in the middle of the incision acetabular notch.

The lesions of the labrum and cartilage were assigned numbers correlating with their position. Using Microsoft 
Excel (Microsoft Corp., Redwood, Washington) a histogram was calculated displaying the frequency distribution for the site of both the acetabular and labral lesions. The mean size of the cartilage lesions was calculated and displayed. In order to simplify the evaluation, left-sided images were inverted to represent right-sided joints.

\section{Results}

Of the 244 hips, 95 were finally excluded (Table III). Of the remaining 149 hips, 57 were classified as the pistol-grip type, of which 17 were combined with coxa profunda deformity, two with protrusio, eight with retroversion and four with coxa vara. Therefore, only 26 patients with a pure pistol-grip deformity remained for analysis. All the hips had an anterior asphericity, as seen on the lateral view. There were 24 men and two women with a mean age of 32 years (21 to 51). The left to right ratio was equally distributed.

Fifty-four hips had coxa profunda, of which 17 were combined with a non-spherical femoral head of the pistolgrip type, 17 had an anteriorly aspherical head on the lateral view and four were combined with coxa vara. Thus, 16 patients with isolated coxa profunda were available for study. There were two men and 14 women with a mean age of 40 years ( 24 to 57 ). The left-to-right ratio was 11 to 5.

In the cam impingement group, most damage was located anterosuperiorly, at the one o'clock position (Fig. $3)$. The mean depth of damage to the cartilage was $11 \mathrm{~mm}$ which corresponded to about one-third of the total depth of the cartilage at this location. ${ }^{15}$ Debonding alone was present in ten hips. A cleavage lesion combined with a defect close to the rim was found in eight hips, and combined with an area of malacia in another four hips. An isolated cleavage lesion was found in two hips and an isolated malacia in one hip. The pathological changes in the labrum had an identical co-location in all cases. The labrum was separated from the cartilage in all 26 hips. Fifteen hips had additional degenerative changes with localised osseous metaplasia of the anteroposterior labrum in four hips, of which two had additional posteroinferior ossification. In five hips the anteroposterior degenerative changes were combined with ossification of the posteroinferior labrum.

In the pincer impingement group alterations of the labrum were more circumferential and were maximal between the 11 and 1 o'clock positions. There was separation between the labrum and the cartilage in five hips, degenerative changes in four and extensive osseous metaplasia in 11 , of which five were circumferentially ossified. The maximum depth of damage to cartilage was at the 12 o'clock position with a mean of $4 \mathrm{~mm}$ (Fig. 4). The damage was restricted to a narrow circumferential band, usually malacia in 15 hips. Debonding was seen in two hips and a cleavage in three. Five of 16 hips (31\%) had posteroinferior roughening or fibrillation of the acetabular cartilage and ten of 16 femoral heads (62\%) had cartilage damage posteroinferiorly.

\section{Discussion}

The pattern of damage to the acetabular cartilage and the labrum depends upon the shape of the hip. In all hips with a cam impingement the acetabular cartilage was damaged in the anterosuperior area of the acetabulum. In all of these a separation of the acetabular cartilage from the labrum was observed. The labrum usually had a stable attachment to the bone, but the acetabular cartilage was torn off the labrum which in some cases showed additional degenerative changes. In the normal hip the acetabular labrum merges with the acetabular cartilage through a transition zone without any gap. ${ }^{16}$ In hips with a pincer impingement the damage was located more circumferentially, usually including only a narrow strip of the acetabular cartilage. The changes in the labrum were co-located with the damage to the cartilage, often presenting as ossification of the labrum.

The patterns of damage in the cam and pincer impingements differ considerably and require a different pathomechanical explanation. The principal problem in the hip with a cam impingement is absent anterior-to-anterolateral waisting of the junction of the femoral neck and head. This is equivalent to a cam, which is an eccentric part added to a rotating device. During flexion the eccentric part slides into the anterosuperior acetabulum and induces compression and shear stresses at the junction between the labrum and the cartilage and at the subchondral tidemark. The labrum is stretched and pushed outwards, and the cartilage is compressed and pushed centrally (Fig. 5), causing a separation between the labrum and cartilage (Fig. 6). Therefore, for so-called undersurface tears of the labrum the correct terminology would be 'separation of the acetabular cartilage from the labrum'. This theory is supported by the observation that in all hips with a cam impingement the labrum had a stable fixation to the acetabular rim but in half of the hips the cartilage was separated from it or was missing. If the labrum was torn off the acetabular rim the acetabular cartilage could be expected to be intact.

The 'pincer' does not cause an impingement because of an asphericity of the femoral head. The dominant feature is that of a deep socket, in which the range of movement of the hip is limited by the overcovering acetabular rim. At the limit of movement the femoral neck abuts against the labrum, which acts like a bumper. The labrum is compressed between the femoral neck and the underlying bone and the force is further transmitted to the acetabular cartilage. The transmission of force to the cartilage is restricted to a narrow band along the acetabular rim (Fig. 7). Repeated microtrauma induces bone growth at the base of the labrum which subsequently ossifies. This is in agreement with the observation of Seldes et $\mathrm{al}^{16}$ who described a labral lesion, with one or more cleavage planes within the substance of the labrum, which was associated with redu- 


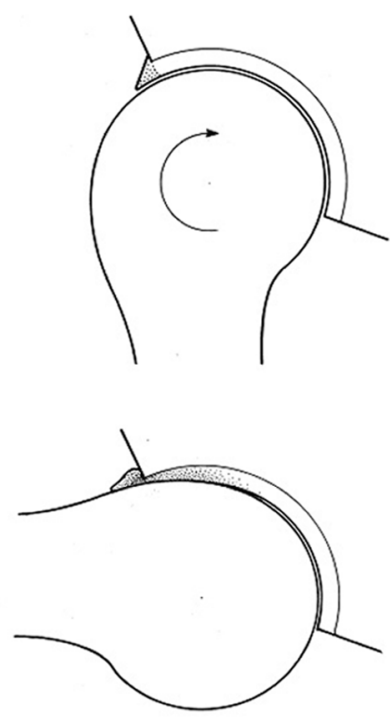

Fig. 5

Diagram of the mechanism of damage in cam impingement on a lateral view of the hip. During flexion the aspherical part of the femoral head is jammed into the acetabulum, compressing the cartilage and pushing it at the same time centrally unti the cartilage is sheared off the subchondral bone.
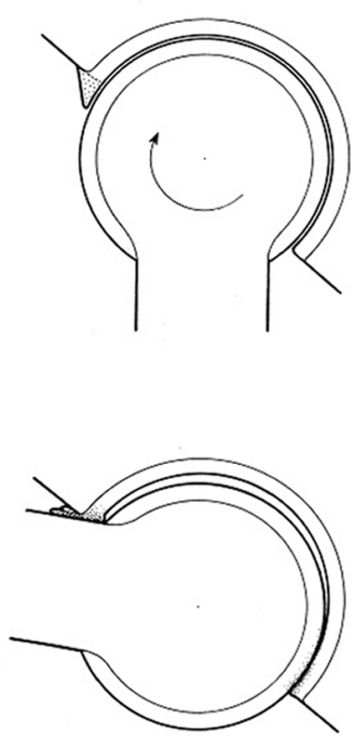

Fig. 7

Diagram of the mechanism of damage in pincer impingement on a lateral view of the hip. During flexion the labrum acts as a buffer between the femoral neck and the acetabulum. Only a small area of acetabular cartilage is subject to compression along the rim. Posteriorly, the femoral head is levered out, creating a contrecoup lesion.

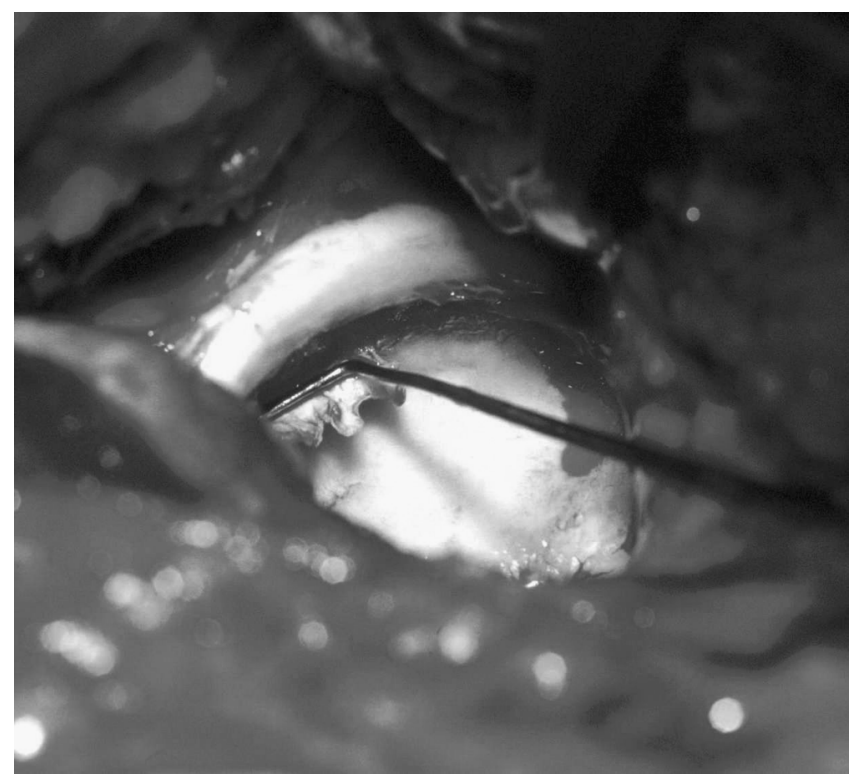

Fig. 6

Intra-operative photograph of a left acetabulum. The cleavage lesion of the acetabular cartilage at the anterosuperior rim is lifted with a probe. The adjacent labrum appears to be normal and has a stable attachment to the bone, but the cartilage is separated from it.

plication of the tidemark and enchondral ossification within the labrum.

In cam impingement the damage to the acetabular joint is located anterosuperiorly. This accords with arthroscopic studies which showed that most of the lesions were found in this area. ${ }^{17-22}$ The damage to the anterosuperior joint is the result of the aspherical extension of the femoral head on to the neck. In flexion this extension squeezes into the anterosuperior acetabulum; it is made worse by internal rotation. This anterolateral extension has been described previously as an anterolateral bone bar which runs medially from the upper anterior part of the greater trochanter over to the femoral head ${ }^{23}$ and is considered to be the last part of the femoral neck to ossify. ${ }^{24,25}$

In coxa profunda, the prototype for pincer impingement, the deep socket limits movement in all directions and leads to a more circumferential pattern of damage. These labral lesions explain the different findings at arthroscopy with more posterior lesions. ${ }^{26-28}$ Since the principal direction of movement is flexion, most of the lesions are located at the anterosuperior acetabular rim. When impingement occurs at the anterosuperior rim and further flexion is enforced, the femoral head begins to sublux posteriorly and, because of the constrained nature of the hip, increased pressure between the posteromedial aspect of the femoral head and the posteroinferior acetabulum occurs. This contrecoup lesion was observed in the femoral head in $62 \%$ and in the posteroinferior acetabulum in $31 \%$. 
Coxa profunda is a prototype of a deep hip, ${ }^{11}$ but there are other conditions in which the acetabulum is deep and in which pincer impingement occurs that are not covered by the definition of Ruelle and Dubois. ${ }^{11}$ Protrusio, acetabular retroversion, ossification of the labrum and a negative acetabular index angle also lead to a pincer impingement.

Cam and pincer impingement are two basic mechanisms and rarely occur in isolation as was the case in our study in which only 26 of 149 hips presented with an isolated aspherical head and 16 with an isolated coxa profunda. Most have a combination of these two basic mechanisms and are classified as mixed cam-pincer impingement. The damage to the cartilage in these cases is usually a combination of the two patterns of damage.

Recently, increasing attention has been given to the association between the labral tear and symptoms of pain in the hip ${ }^{19,21,29}$ and, because of the presence of nerve endings, ${ }^{30}$ there is no doubt that the damaged labrum is a source of pain. However, the cause of labral tears has remained undetermined and treatment has been limited to resection of the damaged labrum. ${ }^{21,22,29}$ Based on the concomitant presence of labral tears and damage to the acetabular cartilage, labral disorders were proposed as a possible cause of early osteoarthritis of the hip. ${ }^{16,21}$ However, our study has shown that cam impingement in particular leads to extensive damage to the acetabular cartilage and that separation between the labrum and the cartilage arises because the cartilage is ripped off the labrum. The tear of the labrum is only part of the pathology and is secondary to impingement. Arthroscopic debridement of the 'labral tear' without attention to the underlying femoroacetabular impingement may explain the poor results reported after isolated arthroscopic labral debridement. ${ }^{21,29,31,32}$

Structural abnormalities at the head-neck junction including pistol-grip deformity, ${ }^{9,33}$ tilt deformity, ${ }^{10}$ femoral anteversion ${ }^{34}$ and other alterations of the femoral neck ${ }^{35}$ have been associated with osteoarthritis of the hip; as bony abnormalities of the acetabulum, such as coxa profunda, protrusio $^{11}$ or retroversion. ${ }^{7,36}$ Some authors have questioned the existence of primary osteoarthritis, or suggested that it was uncommon. ${ }^{35,37}$ However, while they noted that these deformities were present in many patients with socalled 'idiopathic' arthritis, they did not elucidate the pathological mechanism involved. Our study gives an explanation of the mechanism which is responsible for the degeneration of the hip. Based on this knowledge new techniques are being developed to treat femoroacetabular impingement. ${ }^{38-40}$ Existing techniques, like arthroscopy, may be improved if the problem of damage to the labrum and the underlying cause are addressed.

\section{Supplementary Material}

芭 A further opinion by Mr Richard Field is available with the electronic version of this article on our website at www.jbjs.org.uk
No benefits in any form have been received or will be received from a commercial party related directly or indirectly to the subject of this article.

\section{References}

1. Ito K, Minka MA 2nd, Leunig M, Werlen S, Ganz R. Femoroacetabular impingement and the cam-effect: a MRA-based, quantitative anatomical study of the femoral head-neck offset. J Bone Joint Surg [Br] 2001;83-B:171-6.

2. Ganz R, Parvizi J, Beck M, et al. Femoroacetabular impingement: a cause for osteoarthritis of the hip. Clin Orthop 2003;217:112-20.

3. Leunig M, Casillas MM, Hamlet M, et al. Slipped capital femoral epiphysis: early mechanical damage to the acetabular cartilage by a prominent femoral metaphysis. Acta Orthop Scand 2000;71:370-5.

4. Eijer H, Myers SR, Ganz R. Anterior femoroacetabular impingement after femoral neck fractures. J Orthop Trauma 2001;15:475-81.

5. Notzli HP, Wyss TF, Stoecklin CH, et al. The contour of the femoral head-neck junction as a predictor for the risk of anterior impingement. J Bone Joint Surg $[\mathrm{Br}]$ 2002;84-B:556-60

6. Beck M, Leunig M, Parvizi J, et al. Anterior femoroacetabular impingement: midterm results of surgical treatment. Clin Orthop 2004:418:67-73.

7. Reynolds D, Lucas J, Klaue K. Retroversion of the acetabulum: a cause of hip pain. J Bone Joint Surg [Br] 1999;81-B:281-8.

8. Siebenrock KA, Schoeniger R, Ganz R. Anterior femoro-acetabular impingement due to acetabular retroversion: treatment with periacetabular osteotomy. J Bone Joint Surg [Am] 2003;85-A:278-86.

9. Stulberg SD, Cordell LD, Harris WH, Ramsey PL, MacEwen GD. Unrecognized childhood hip disease: a major cause of idiopathic osteoarthritis of the hip. In: The hip: Proc of the third open scientific meeting of The Hip Society. St Louis: CV Mosby Co., 1975:212-28.

10. Murray RO. The aetiology of primary osteoarthritis of the hip. Br J Radiol 1965;38: 810-24.

11. Ruelle $\mathbf{M}$, Dubois $\mathbf{J L}$. The protrusive malformation and its arthroscopic complication. I: radiological and clinical symptoms. Rev Rhum Mal Osteoartic 1962;29:476-89 (in French).

12. Siebenrock KA, Kalbermatten DF, Ganz R. Effect of pelvic tilt on acetabular retroversion: a study of pelves from cadavers. Clin Orthop 2003;407:241-8.

13. Tönnis $\mathbf{D}$. Congenital dysplasia and dislocation of the hip in children and adults. New York: Springer, 1987:167.

14. Eijer H, Leunig M, Mahomed MN, Ganz R. Cross-table lateral radiograph for screening of anterior femoral head-neck offset in patients with femoro-acetabular impingement. Hip 2001;11:37-41.

15. Oberländer W, Kurrat HJ, Breul R. Examination of the extension of the osseous facies lunata: a functional study. Z Orthop Inre Grenzgeb 1978;116:675-82 (in German).

16. Seldes RM, Tan V, Hunt J, et al. Anatomy, histologic features, and vascularity of the adult acetabular labrum. Clin Orthop 2001;382:232-40.

17. Byers PD, Contepomi CA, Farkas TA. A post mortem study of the hip joint: including the prevalence of the features of the right side. Ann Rheum Dis 1970;29:15-31.

18. Byrd JW. Labral lesions: an elusive source of hip pain. Arthroscopy 1996;12:603-12.

19. Fitzgerald RH Jr. Acetabular labrum tears: diagnosis and treatment. Clin Orthop 1995;311:60-8.

20. Lage LA, Patel JV, Villar RN. The acetabular labral tear: an arthroscopic classification. Arthroscopy 1996;12:269-72.

21. McCarthy JC, Noble PC, Schuck M, Wright J, Lee J. The role of labral lesions to development of early degenerative hip disease. Clin Orthop 2001;393:25-37.

22. Santori N, Villar R. Arthroscopic findings in the initial stages of hip osteoarthritis Orthopedics 1999;22:405-9.

23. Angel JL. The reaction area of the femoral neck. Clin Orthop 1964;32:130-42.

24. Odgers PNB. Two details about the neck of the femur: (1) the eminentia, (2) the empreinte. J Anat 1931;45:352-62.

25. Sudeck P. Zur anatomie und aetiologie der coxa vara adolescentium: zugleich ein beitrag zur der lehre von dem architektonischen bau des coxalen femurendes. Arch Clin Chirurg 1899:59:504-24 (in German).

26. Hase T, Ueo T. Acetabular labral tear: arthroscopic diagnosis and treatment. Arthroscopy 1999;15:138-41.

27. Ikeda T, Awaya G, Suzuki S, Okada Y, Tada H. Torn acetabular labrum in young patients: arthroscopic diagnosis and management. J Bone Joint Surg [Br] 1988;70-B: 13-16.

28. Suzuki S, Awaya G, Okada Y, et al. Arthroscopic diagnosis of ruptured acetabular labrum. Acta Orthop Scand 1986;57:513-15.

29. Farjo LA, Glick JM, Sampson TG. Hip arthroscopy for acetabular labral tears. Arthroscopy 1999;15:132-7. 
30. Kim YT, Azuma H. The nerve endings of the acetabular labrum. Clin Orthop 1995; 320:176-81.

31. Eriksson E, Arvidsson I, Arvidsson H. Diagnostic and operative arthroscopy of the hip. Orthopedics 1986;9:169-76.

32. O'Leary JA, Berend K, Vail TP. The relationship between diagnosis and outcome in arthroscopy of the hip. Arthroscopy 1991;17:181-8.

33. Goodman DA, Feighan JE, Smith AD, et al. Subclinical slipped capital femoral epiphysis: relationship to osteoarthritis of the hip. J Bone Joint Surg [Am] 1997;79-A: 1489-97.

34. Tönnis D, Heinecke A. Acetabular and femoral anteversion: relationship with osteoarthritis of the hip. J Bone Joint Surg [Am] 1999;81-A:1747-70.

35. Harris WH. Etiology of osteoarthritis of the hip. Clin Orthop 1986;213:20-33.
36. Giori NJ, Trousdale RT. Acetabular retroversion is associated with osteoarthritis of the hip. Clin Orthop 2003;417:263-9.

37. Solomon L. Patterns of osteoarthritis of the hip. J Bone Joint Surg [Br] 1976;58-B: 176-84.

38. Gautier E, Ganz K, Krugel N, Gill T, Ganz R. Anatomy of the medial femoral circumflex artery and its surgical implications. J Bone Joint Surg [Br] 2000;82-B: 679-83.

39. Ganz R, Gill TJ, Gautier E, et al. Surgical dislocation of the adult hip: a technique with full access to femoral head and acetabulum without the risk of avascular necrosis. J Bone Joint Surg [Br] 2001;83-B:1119-24.

40. Lavigne M, Parvizi J, Beck M, et al. Anterior femoroacetabular impingement: part I: techniques of joint preserving surgery. Clin Orthop 2004;418:61-6. 